\title{
Bio-Active Nano-Diamond Designer Materials and Dentures: From Design to Application
}

\author{
V. Tamara Perchyonok ${ }^{1 *}$, John Souza², Shengmiao Zhang ${ }^{3}$, Desigar Moodley ${ }^{4}$ and Sias Grobler ${ }^{4}$ \\ ${ }^{1}$ VTPCHEM PTY LTD, Glenhuntly, Melbourne, Australia \\ ${ }^{2}$ Department of Prosthetics, TAFE Queensland, 66 Ernest Street, South Brisbane, Australia \\ ${ }^{3}$ School of Material Science and Engineering, East China University of Science and Technology, 130 Meilong Road, Shanghai, China \\ ${ }^{4}$ Oral and Dental Research Institute, School of Dentistry, University of Western Cape, Cape Town, South Africa
}

\begin{abstract}
Objective: The present study aims to design functional biomaterials and evaluate performance of nano-diamond: chitosan based bio-active containing PMMA (polymethyl methacrylate) materials towards application in treatment and prevention of denture stomatitis and associated conditions in denture wearers.

Methods: The bio-active nano-diamond modified PMMA were prepared by dispersion of the corresponding component in glycerol and acetic acid with the addition of chitosan gelling agent. The release behaviors at physiological $\mathrm{pH}$ and also under acidic conditions and stability of the antioxidant-chitosan-nano-diamond were also evaluated. Mechanical performance such as tensile strength and compressive strength were measured as well bio-adhesive studies were investigated in order to assess the suitability of these designer materials.

Results: The bio-active nano-diamond modified PMMA materials showed a high adhesive force and they only swelled slightly in the aqueous medium. Bioactive release suggested prolonged release of the therapeutic agent from the hydrogels. The hydrogels also had significant free radical defense capability.

Conclusion: In this study we demonstrated that the newly prepared bio-active modified PMMA resins are suitable novel bio-active materials capable of comparable performance with the conventional PMMA materials with additional benefit of therapeutic bioactive release as well as potential antimicrobial properties to be demonstrated in vitro. Our findings might be thus a step forward towards the development of alternative non antibiotic based strategies targeting bacterial infections.
\end{abstract}

Keywords: Chitosan; Nano-diamond; Bio-active; PMMA; Drug delivery systems; Free radicals

\section{Introduction}

The initial interaction between pathogenic bacteria and host cells is one of the critical steps leading to host colonization [1]. These first adhesion events allow host-pathogen recognition and prevent bacteria from being washed out by the host and are generally mediated by species proteins called adhesins. C. albicans binds various bacterial species, participating in polymicrobial interactions in the normally healthy host [2]. One of these is the oral commensal bacterium Streptococcus gordonii [3]. Als3 is one of eight C. albicans Als proteins (Als1-Als7, Als9), large cell-surface glycoproteins that primarily function in adhesive interactions [4].

Nano-diamond particles (NDs) are emerging as particularly wellsuited for biological applications due to their biocompatibility [5-10]. It is indeed because of this feature that diamond nanoparticles should also be explored for anti-bacterial applications. While nano-diamond conjugates have shown their interest for the detection and removal of bacteria in solution, their potential for the efficient inhibition of Alsmediated binding phenomena has however not been fully explored [11].

Chitosan, which is a biologically safe biopolymer as well as an antioxidant, has been proposed as a bio-adhesive polymer and is of continuous interest to us due to its unique properties and flexibility in a broad range of oral applications reported by others and ourselves recently [12-15].

Lentinus edodes, known as shiitake mushroom, has received great attention due to positive health effects, including anti-tumour and hypo-cholesterolemic activity [12], related to the presence of $\beta$-glucans [13]. Propolis is a resinous substance produced by bees with antibacterial, antifungal, antiviral, and anti-inflammatory activities $[14,15]$. Propolis is bacteriostatic and bactericidal in high concentration [16]. Propolis has antimicrobial activity against gram-positive bacteria, e.g., S. aureus, but limited action against gram-negative bacteria and also against some fungi, e.g., C. albicans $[17,18]$. The copaiba tree is native to Latin America and Occidental Africa [19]. There are more than 20 species of copaiba in Brazil, and the most commonly described effects are anti-inflammatory, analgesic, antibacterial and antitumoral activities [20-22].

The present study aims to design functional biomaterials, evaluate the performance of chitosan: nano-diamonds based bio-active PMMA (polymethyl methacrylate) materials and investigate the potential applications of the newly developed materials for and prevention of denture stomatitis and associated conditions in denture wearers, while the performance of the material is not compromised in vitro.

\section{Materials and Methods}

Propolis Brazilian (Red, Natura Nectar, USA), Copaiba Oil (Laboratorio Sao Lucas, Brazil) and Shiitake powder (Border herbal

*Corresponding author: Dr. V. Tamara Perchyonok, VTPCHEM PTY LTD, Glenhuntly, Melbourne, 4215, Australia, Tel: (+61) 414596304; E-mail: tamaraperchyonok@gmail.com

Received October 19, 2015; Accepted November 25, 2015; Published November 30, 2015

Citation: Perchyonok VT, Souza J, Zhang S, Moodley D, Grobler S (2015) Bio-Active Nano-Diamond Designer Materials and Dentures: From Design to Application. Dentistry 5: 344. doi:10.4172/2161-1122.1000344

Copyright: ( 2015 Perchyonok VT, et al. This is an open-access article distributed under the terms of the Creative Commons Attribution License, which permits unrestricted use, distribution, and reproduction in any medium, provided the original author and source are credited. 
health, Australia) were purchased from a commercial supplier (Wholesale Chemist, QLD, Australia) and used without further purification. (-)-Epigallocatechin gallate (EGCG) from green tea, 95\%; (-)-epicatechin gallate (ECG) from green tea, 98\%; (-)-epigallocatechin (EGC) from green tea, 95\%; (-)-epicatechin (EC), 90\%; gallic acid (GA) purity not specified; 6-hydroxy-2,5,7,8-tetramethylchromane-2carboxylic acid (trolox), 95\%; Folin-Ciocalteu reagent, ferric chloride, Tween-20 and 2,20-azino-bis(3-ethylbenzothiazoline-6-sulfonic acid) diammonium salt (ABTS) were purchased from Sigma-Aldrich Company Ltd. (Australia). Chitosan (Aldrich, Australia), glycerol (Sigma, USA), glacial acetic acid (E. Merck, Germany) were used as received. The degree of de-acetylation of typical commercial chitosan used in this study is $87 \%$. Chitosan with molecular weight $2.5 \times 10^{3} \mathrm{KD}$ was used in the study. Gelatin in powder form was purchased from Shanghai Chemical Reagent Co., (Shanghai, China) with the numberaverage molecular weight $(\mathrm{Mn})$ of about $8.7 \times 10^{4}$. The isoelectric point is $4.0=5.0$. Nano-diamonds where purchased from Ebersoles, $(25$ carats, size $0-2 \mu$, Grit 14,000 ) and used as received.

\section{Preparation of nano-diamond bioactive containing PMMA materials: general protocol}

The bioactive containing gel was prepared by dispersion of $0.2 \mathrm{~g}$ of commercially available bioactives (Propolis, Copaiba oil or Shiitake powder) and nano-diamond powder $(0.08 \mathrm{~g})$ in glycerol $(5 \% \mathrm{w} / \mathrm{w})(1$ $\mathrm{ml}$ ) using a mortar and a pestle following generic protocol [9-11]. $10 \mathrm{ml}$ of glacial acetic acid $(3 \% \mathrm{w} / \mathrm{w})$ was then added by continuous mixing and finally chitosan $(10 \%$ chitosan $\mathrm{w} / \mathrm{w})$ polymer was spread on the surface of the dispersion and mixed well to form the required gel and then mixed into a PMMA resin prior to setting.

The strength of the prepared gel $(10 \mathrm{~g})$ is $0.2 \mathrm{~g}$ of propolis, copaiba oil or shiitake mushrooms extract in each gram of the base and $0.08 \mathrm{~g}$ of nano-diamond in each gram of the base. The total phenolic concentration was quantified using Rocha et al. and described by Waterman and Mole with some modifications $[23,24]$.

\section{Swelling/weight loss tests and bioactive release}

The swelling/weight loss tests were performed when triplicates of each samples composition (approximately $2 \mathrm{~cm}^{2}$, weight normalized) were immersed in $2 \mathrm{ml}$ of different fluids at $37^{\circ} \mathrm{C}$ for each time interval studied $(1,2,4,24$, and $96 \mathrm{~h})$. Two different media were used in accordance with the ISO 10993-9 standard. The first media was Phosphate Buffered Saline (PBS, Sigma Aldrich), intended to mimic the inorganic phase of human plasma [9-11]. The other media was PBS with a reduced $\mathrm{pH}$ which was intended to simulate the local inflammatory environment of the wounds [9-11]. This is termed Solution pH 4.0. The $\mathrm{pH}$ was lowered using lactic acid (Sigma Aldrich). The fluid absorption of each sample was calculated according to Equation 1 to obtain their swelling degree $(\mathrm{SD}) . \mathrm{W}_{\mathrm{S}}$ is the weight of the sample at each time interval (swollen weight) and $\mathrm{W}_{\mathrm{D}}$ is the dry weight before swelling [20]. After 4 days of immersion, the samples were dried and weighed and weight loss $(\mathrm{WL})$ is calculated using Equation 2, where $\mathrm{W}_{\mathrm{D}}$ and $\mathrm{W}_{\mathrm{DS}}$ are the weight of the dried samples before and after swelling tests, respectively.

$$
\begin{aligned}
& \mathrm{SD}=100 \frac{\left(\mathrm{W}_{\mathrm{S}}-\mathrm{W}_{\mathrm{D}}\right)}{\mathrm{W}_{\mathrm{D}}} \% \\
& \mathrm{WL}=100 \frac{\left(\mathrm{W}_{\mathrm{S}}-\mathrm{W}_{\mathrm{DS}}\right)}{\mathrm{W}_{\mathrm{DS}}} \%
\end{aligned}
$$$$
\text { (Equation 1) }
$$

To analyze the bio-active release (propolis, copaiba oil and shiitake mushrooms) based on the total phenolic concentration, the swelling media was analyzed after 1, 2, 24, and $96 \mathrm{~h}$ of immersion via UV-Visible spectrometer, from 300 to $800 \mathrm{~nm}$, using polystyrene cuvettes [21]. For quantification of the amount of propolis released, a standard curve was created by diluting the original propolis in isopropanol resulting in several aliquots of known concentration, which were then analyzed in the same wavelength range. The area of the peak of these aliquots (of known concentration of bio-additive) was calculated and used to compare with those of the bio-additive released by the samples.

\section{Tensile strength testing of the material}

Tensile testing was conducted using Instron 5565. Following American Standardized Testing Materials Standard D3039, rectangular samples were approximately 6-8 $\mathrm{mm}$ in length, $1 \mathrm{~mm}$ in width and 1 $\mathrm{mm}$ in thickness, and tested with a gauge length of $3.5 \pm 0.4 \mathrm{~mm}$ [24]. Samples were elongated at a rate of $1 \%$ of gauge length per second. The cross-sectional area of samples was evaluated using Image J image analysis software [25].

\section{Compressive strength}

Compressive strength test samples were placed in the measuring apparatus in an appropriate manner and cross-sectional area of each sample $\left(\mathrm{mm}^{2}\right)$ was determined. A compressive load $(\mathrm{N})$ was applied at a crosshead speed of $1.3 \mathrm{~mm} / \mathrm{min}$ [26]. The compressive strength $(\mathrm{MPa})$ was measured at the sample fracture point. Mean, average, and mode in each group were calculated and normal distribution curve was evaluated. One-way ANOVA, followed by multiple comparison test (Scheffé's test), was used for statistical analysis. Statistical significance was set at $\mathrm{p}<0.05$.

\section{Bio-adhesive investigation}

Bio-adhesion studies were done using a Chatillon apparatus for force measurement. This method determines the maximum force and work needed to separate two surfaces in intimate contact [27]. The modified nano-diamond biomaterials $(0.1 \mathrm{~g})$ were homogeneously spread on a $1 \mathrm{~cm}^{2}$ disk and then the disks were fixed to the support of the tensile strength tester using double sided adhesive. The bio-active modified PMMA material was brought into contact with a slice of pig ear skin was established in order to imitate adhesion of the gel to the 'oral mucosa prototype system' structure. After a preset contact time of 1 min under contact strength of $0.5 \mathrm{~N}$, the 2 surfaces were separated at a constant rate of displacement of $1 \mathrm{~mm} / \mathrm{s}$. The strength was recorded as a function of the displacement, which allowed to determine the maximal detachment force, Fmax, and the work of adhesion, W, which was calculated from the area under the strength-displacement curve [27].

\section{Results}

\section{SEM Images of the newly prepared biomaterials}

The SEM images were obtained for selective nano-diamond bioactive modified PMMA resins to characterize the microstructure of the freeze-dried and are presented in Figure 1. SEM observations of nano-diamond PMMA-based samples revealed a smooth surface with the formation of the valleys and crests, which could be attributed to the presence of some aqueous medium in the preparation of modified materials.

\section{Mechanical properties investigated}

Compression test: PMMA has adequate tensile and compressive strength for complete and partial dentures [28]. The compression 


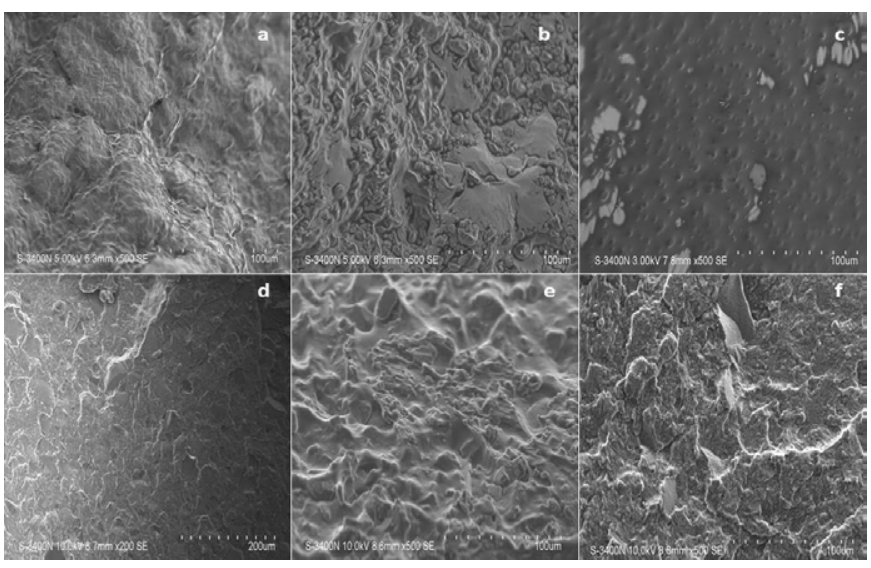

a. Shiitake/Nanodiamond/PMMA, b. Copaiba/Nanodiamond/PMMA, c. Propolis (Brazilian)/Nanodiamond/PMMA, d. Shiitake/Nanodiamond/Chitosan/ PMMA, e. Copaiba/Nanodiamond/Chitosan/PMMA and f. Propolis (Brazilian)/ Nanodiamond/Chitosan/PMMA

Figure 1: SEM photographs of interior morphology of the selected gels under investigation.

behavior for composite prosthetic dentures represents the important mechanical properties specialization when using the polymer matrix materials. The compression strength values results obtained from compression tests are carried out for all bioactive prepared materials and results are summarized in Figure 2.

Tensile strength of the bio-active functionalized materials: The tensile behavior for composite prosthetic dentures represents the important mechanical properties specialization when using the polymer matrix materials and is summarized in Figure 3 . The addition of the bioactive compounds such as shiitake extract, copaiba oil or Brazilian propolis in combination with nano-diamond powder has not influenced significantly the tensile strength of the bioactive PMMA material.

Swelling/weight loss tests and bioactive release: The swelling characteristics of the bio-active modified materials at $\mathrm{pH} 7.0$ and $\mathrm{pH} 4$ are shown in Figure 4.

The amount of bio-actives, nano-diamond chitosan (such as Brazilian propolis, shiitake mushroom extract and copaiba oil) release in swelling media was analyzed after 1, 2, 24, and $96 \mathrm{~h}$ of immersion (Figure 5). The bioactive phenolic release by polymeric systems usually occurs in two steps: the release of certain amounts of bioactive phenolic component in the first day of swelling as well as a prolonged release in some cases [28].

Bio-adhesion of PMMA modified materials: Higher adhesiveness of the modified PMMA resins is desired to maintain an intimate contact oral mucosa and the prosthetic device such as full or partial denture, therefore bio-adhesion between the newly prepared modified bio-active containing PMMA was tested against pig ear skin structure and results are summarized in Table 1.

\section{Discussion}

\section{Compressive strength of new biomaterials}

The addition of the bioactive compounds such as shiitake extract, copaiba oil or Brazilian propolis in combination with nano-diamond had significantly influenced into the compression strength of the bio- active PMMA material. Also upon incorporation of nano-diamondchitosan-bio-active combination $(10 \% \mathrm{w} / \mathrm{w})$ into the PMMA material the compressive strength of the new bioactive material was significantly increased in comparison to the standard PMMA material.

\section{Tensile strength of bioactive PMMA materials}

Also upon incorporation of nano-diamond-chitosan-bio-active combination $(10 \% \mathrm{w} / \mathrm{w})$ into the PMMA material the tensile strength of the new bioactive material was significantly increased in comparison to the standard PMMA material. The slight increase of tensile strength is probably due to the potential action interference of the bio-actives and their antioxidant capacity with the polymerization rates of the PMMA presence of chitosan acts as the protective host of the excess of free radical formation and therefor some in the tensile as well as compressive strength is observed. The results are consistent with the literature $[29,30]$ and more detailed investigations into mechanistic interaction of chitosan/bioactive/PMMA resin are currently on the way in our laboratory.

\section{Swelling/weight loss tests and bioactive release}

Swelling has not been affected significantly in case of either incorporation of bioactive/nano-diamond or bioactive/chitosan/ nano-diamond did not increased in the case at either $\mathrm{pH}$. No definite trend in swelling with composition was observed. Though PMMA is

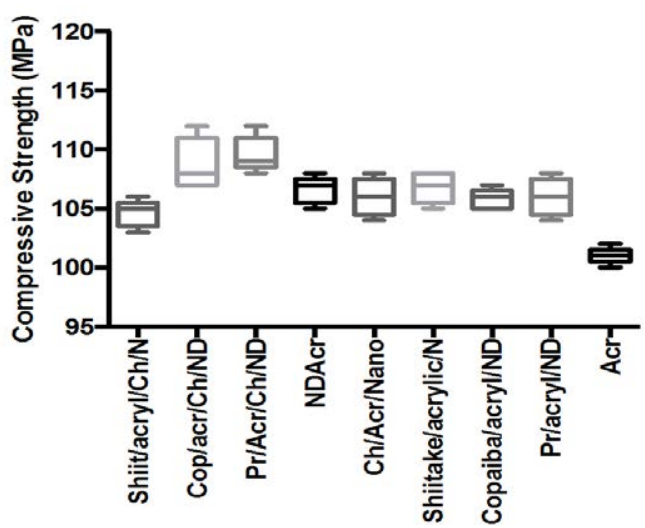

Figure 2: Summary of compressive strength of the bio-active functionalized biomaterials.

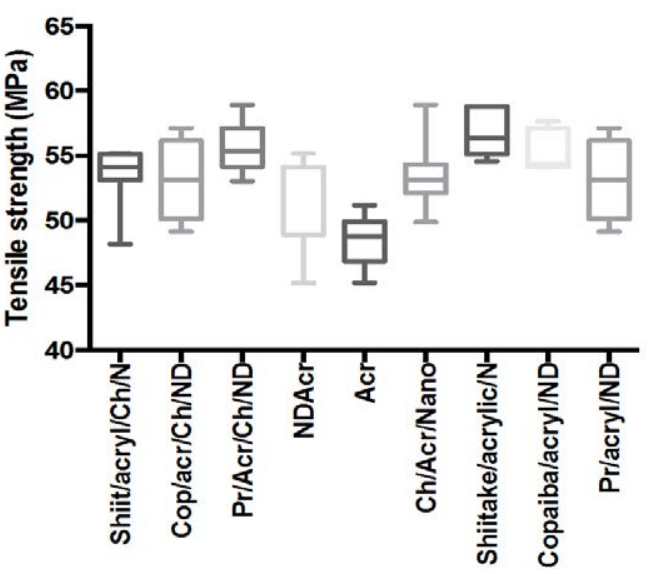

Figure 3: Tensile strength of the bio-active functionalized materials. 

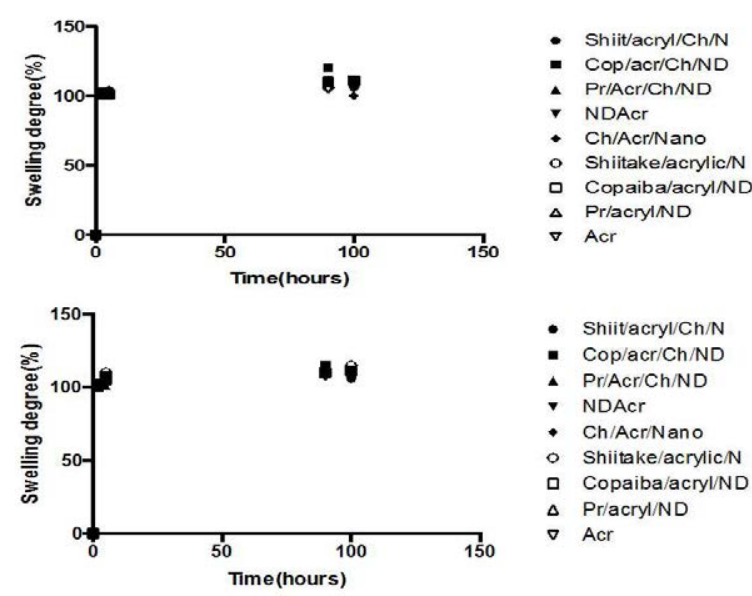

- Shiitacryl/Ch/N

- $\mathrm{Cop} / \mathrm{acr} / \mathrm{Ch} / \mathrm{ND}$

- $\mathrm{Pr} / \mathrm{Acr} / \mathrm{Ch} / \mathrm{ND}$

- NDACr

- Ch/AcriNano

Shiitake/acrylic/N

Copaiba/acryl/ND

$\triangle \mathrm{Pr} / \mathrm{acry} / \mathrm{ND}$

Acr

$4 \mathrm{a}=$ Swelling at $\mathrm{pH}=4 ; 4 \mathrm{~b}=$ Swelling at $\mathrm{pH}=7$

Figure 4: Swelling at different $\mathrm{pH}$ values.

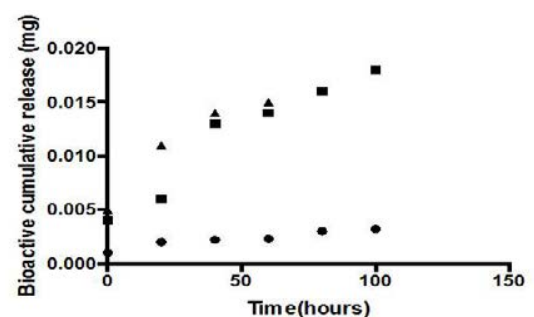

- Shiit/acryl/Ch/N

- Cop/acr/Ch/ND

- $\mathrm{Pr} / \mathrm{Acr} / \mathrm{Ch} / \mathrm{ND}$

$\mathbf{4 b}$

$4 a$

$$
\text { Pr/Acr/Ch/ND }
$$

a

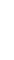

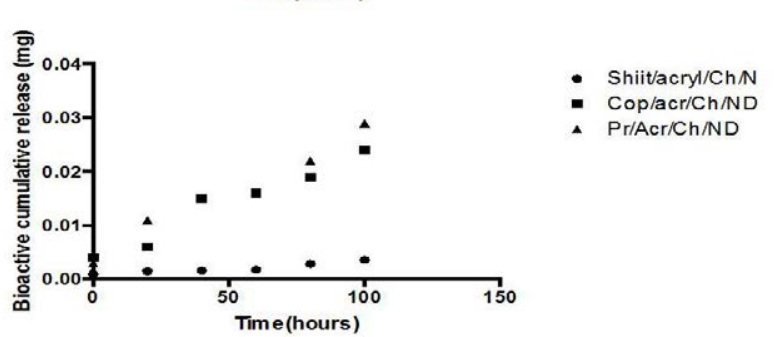

b

The ND/Ch/PMMA-bioactive samples were immersed in (a) PBS and (b) Solution $\mathrm{pH} 4.0$ and the bioactive (such as copaiba oil, propolis and shiitake extract delivered was quantified after regular intervals of time for 4 days.

Figure 5: Bioactive cumulative release profile of Nano-diamond/Chitosan/ PMMA-bioactive samples.

a hydrophobic polymer, the acidic environment may hydrolyze the methacrylate group to some extent conferring hydrophilic nature to the copolymer. The in depth investigation between the nature of the functional surface interaction of nano-diamond-chitosan-bio-active is currently under investigation in our laboratory.

A trend could be observed in all curves after 4 days of immersion; there was a high bioactive release in the initial hours and the cumulative release reached constant values up to 1 day of immersion. No prolonged release was observed. The amount of bioactive release in swelling media was analyzed after 1, 2, 24, and $96 \mathrm{~h}$ of immersion (Figure 5). The bioactive release by polymeric systems usually occurs in two steps: the release of certain amounts of bio-active in the first day of swelling as well as a prolonged release in some cases [31-39]. Nonetheless, the samples released more bioactive to PBS than to Solution $\mathrm{pH} 4.0$, probably indicating that the propolis release can be influenced by the media $\mathrm{pH}$. The detailed mechanistic investigations are currently under investigation in our laboratory.

\section{Bio-adhesion of PMMA modified materials}

Chitosan hydrogels and chitosan/nano-diamond combinations showed the highest adhesive force and the work of adhesion this can be expected because of the well-known intrinsic bioadhesive properties of chitosan as well as favorable functional surface of nano-diamondchitosan and its favorable interaction with the bio-active components [40]. The adequate water absorption capacity together with the cationic nature which promotes binding to the negative surface of skin structure can also interpret this results. The additional benefits of the incorporation of the nano-diamonds as a highly functionalized surface which is able to interact with the surface of the skin are currently under investigation in our laboratory.

\section{In vitro application of the functionalized biomaterials as protective biofilm-inhibitory surface modification.}

The first step for successful colonisation of mucosal surfaces or any other surface by C. albicans is adhesion [41]. Although among the functions of propolis, the fungicidal property has already been shown, in this study, we aimed to verify its effectiveness in inhibiting the adhesion of C. albicans biofilm on a denture surface (Figure 6).

It would be more desirable to develop antimicrobial material characterized by anti-adherent effect whose primary scope is the prevention, not a treatment that might cause undesirable interactions

\begin{tabular}{|c|c|c|}
\hline Bio-materials & $\begin{array}{c}\text { Adhesive Force (N) } \mathbf{\pm} \\
\text { SD (Skin) }\end{array}$ & $\begin{array}{c}\text { Work of Adhesion (N } \\
\text { cm) } \pm \text { SD (Skin) }\end{array}$ \\
\hline Shiitake/PMMA/ND & $1.16 \pm 0.320$ & $4.35 \pm 0.48$ \\
\hline Shiitake/PMMA/Chitosan/ND & $1.23 \pm 0.32$ & $4.83 \pm 0.42$ \\
\hline Copaiba/PMMA/ND & $1.26 \pm 0.29$ & $4.28 \pm 0.31$ \\
\hline Copaiba/PMMA/Chitosan/ND & $1.35 \pm 0.40$ & $4.35 \pm 0.65$ \\
\hline Propolis/PMMA/ND & $1.52 \pm 0.28$ & $4.87 \pm 0.42$ \\
\hline Propolis /PMMA/Chitosan/ND & $1.24 \pm 0.22$ & $4.81 \pm 0.39$ \\
\hline PMMA & $1.10 \pm 0.34$ & $4.41 \pm 0.36$ \\
\hline Chitosan/PMMA & $0.97 \pm 0.30$ & $4.97 \pm 0.42$ \\
\hline
\end{tabular}

Table 1: Bio-adhesion table.

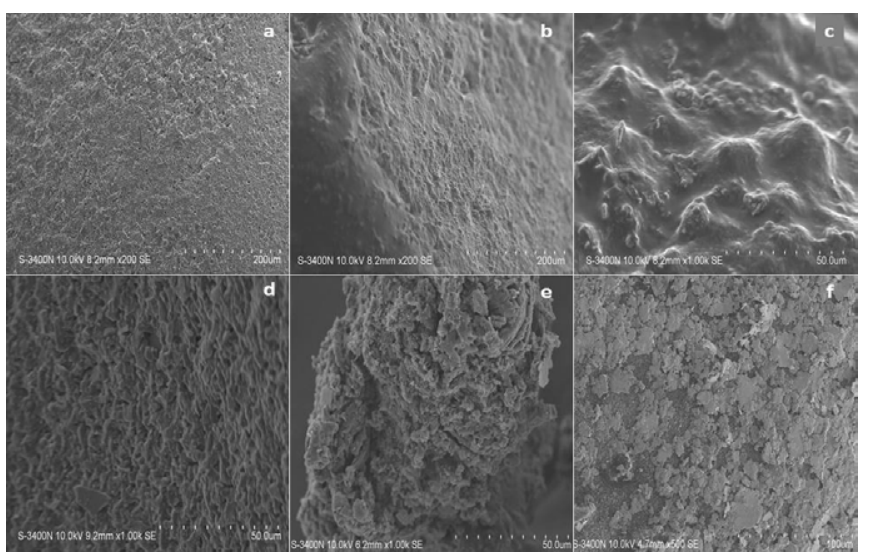

a. Shiitake/Nanodiamond/PMMA, b. Copaiba/Nanodiamond/PMMA, c. Propolis (Brazilian)/Nanodiamond/PMMA, d. Shiitake/Nanodiamond/Chitosan/ PMMA, e. Copaiba/Nanodiamond/Chitosan/PMMA and f. Propolis (Brazilian)/ Nanodiamond/Chitosan/PMMA

Figure 6: Surfaces of the materials after exposure to artificial saliva and oxygen as an in vitro model for the biofilm formation after 3 weeks of storage. 
with host tissues. It is well documented that hydrophobic interaction could also play an important role in bacterial adherence to nanodiamond- chitosan-bioactive-PMMA surfaces because the electrical forces are minor to the hydrophobic forces, since adherence to a considerable extent occurs even in the presence of this repulsive force $[41,42]$. The detailed investigation into the physical nature of the process is currently under investigation in our laboratory. Our results are in accordance with the literature report show that while ND-menthol particles are non-toxic to both pathogens, they show significant antibiofilm activity. The presence of ND-menthol particles reduces biofilm formation more efficiently than free menthol, unmodified oxidized NDs and ampicillin, a commonly used antibiotic.

\section{Conclusion}

In this study we demonstrated that the newly prepared bio-active modified PMMA resins are suitable novel bio-active materials capable of comparable performance with the conventional PMMA materials with additional benefit of therapeutic bioactive release as well as potential antimicrobial properties to be demonstrated in vitro. Our findings might be thus a step forward towards the development of alternative non antibiotic based strategies targeting preventing oral candidiasis and related conditions.

\section{References}

1. Blignaut E, Pujol C, Lockhart S, Joly S, Soll DR (2002) Ca3 fingerprinting of Candida albicans isolates from human immuno-deficiency virus-positive and healthy individuals reveals a new clade in South Africa. J Clin Microbiol 40: 826-836.

2. Chen MH, Shen ZM, Bobin S, Kahn PC, Lipke PN (1995). Structure of Saccharomyces cerevisiae alpha-agglutinin. Evidence for a yeast cell wall protein with multiple immunoglobulin-like domains with atypical disulfides. $J$ Biol Chem 270: 26168-26177.

3. De Bernardis F, Sullivan PA, Cassone A (2001) Aspartyl proteinases of Candida albicans and their role in pathogenicity. Med Mycol 39: 303-313.

4. Fu Y, Ibrahim AS, Sheppard DC, Chen YC, French SW, et al. (2002) Candida albicans Als1p: an adhesin that is a downstream effector of the EFG1 filamentation pathway. Mol Microbiol 44: 61-72.

5. Gaur NK, Klotz SA, Henderson RL (1999) Overexpression of the Candida albicans ALA1 gene in Saccharomyces cerevisiae results in aggregation following attachment of yeast cells to extracellular matrix proteins, adherence properties similar to those of Candida albicans. Infect Immun 67: 6040-6047.

6. Barras A, Martin FA, Bande O, Baumann JS, Ghigo JM, et al. (2013) Glycanfunctionalized diamond nanoparticles as potent E. coli anti-adhesives. Nanoscale 5: 2307-2316.

7. Ray PC, Khan SA, Singh AK, Senapati D, Fan Z (2012) Nanomaterials for targeted detection and photothermal killing of bacteria. Chem Soc Rev 41 : 3193-3209.

8. Herman A, Herman AP (2014) Nanoparticles as antimicrobial agents: their toxicity and mechanisms of action. J Nanosci Nanotechnol 14: 946-957.

9. Allaker RP, Memarzadeh K (2014) Nanoparticles and the control of oral infections. Int J Antimicrob Agents 43: 95-104.

10. Marcon L, Riquet F, Vicogne D, Szunerits S, Bodartb JF, et al. (2010) Cellular and in vivo toxicity of functionalized nanodiamond in Xenopus embryos. $J$ Mater Chem 20: 8064-8069.

11. Perchyonok VT, Vanessa R Zhang S, Basson NJ, Grobler SR (2015) Bioinspired-Interpenetrating Network (IPNs) Hydrogel (BIOF-INPs) and TMD in vitro: Bioadhesion, drug release and build in free radical detection and defense. OJST 5: 53-56.

12. Lindequist $U$, Niedermeyer TH, Jülich WD (2005) The pharmacological potential of mushrooms. Evid Based Complement Alternat Med 2: 285-299.

13. Chu KT, Xia L, Ng TB (2005) Pleurostrin, an antifungal peptide from the oyster mushroom. Peptides 26: 2098-2103.
14. Zumla A, Lulat A (1989) Honey-a remedy rediscovered. J R Soc Med 82: 384385 .

15. Havsteen B (1983) Flavenoids, a class of natural products of high pharmacological potency. Biochem Pharmacol 32: 1141-1148.

16. Lepekhin VN, Leonova TA (1970) Antimicrobial properties of propolis. Stomatologiia (Mosk.) 49: 16-19.

17. Gronstol H, Aspoy E (1977) A new selective medium for the isolation of Listeria monocytogenes. Nord Vet Med 29: 440-445.

18. Cizmarik J, Trupl J (1976) Action of propolis on dermatophytes. Pharmazie 31: 55.

19. Vasconcelos KRF, Veiga Junior VF, Rocha WC, Bandeira MFCL (2008) In vitro evaluation of antibacterial activity of a dental cement-based oleoresin of Copaifera Hayne multijuga. Braz J Pharmacogn 18(S): 733-738.

20. Santos AO, Ueda-Nakamura T, Dias Filho BP, Veiga Junior VF, Pinto AC, et al. (2008) Antimicrobial activity of Brazilian copaiba oils obtained from different species of the Copaifera genus. Mem Inst Oswaldo Cruz. 103: 277-281.

21. Ferrari M, Pagnoni UM, Pelizzoni F, Lukes V, Ferrari G (1971) Terpenoids from Copaifera langsdorffi. Phytochemistry 10: 905-907.

22. Basile AC, Sertié JA, Freitas PC, Zanini AC (1988) Antiinflamatory activity of oleoresin from Brazilian Copaifera. J Ethnopharmacol 22: 101-109.

23. Rocha A, Morais A (2001) Polyphenoloxidase activity and total phenolic conten as related to browning of minimally processed 'Jonagored' apple, J Sci Food Agric 82: 120-126.

24. Waterman PG, Mole S (1994) Analysis of Phenolic Plant Metabolites. Blackwell Scientific Publications, Oxford.

25. Tugut $F$, Akin H, Mutaf B, Akin GE, Ozdemir AK (2012) Strength of the bond between a silicone lining material and denture resin after Er:YAG laser treatments with different pulse durations and levels of energy. Lasers Med Sci 27: 281-285.

26. Al-Athel M, Jagger R, Jagger D (2002) Effect of ageing on the bond strength of a permanent denture soft lining material. J Oral Rehabil 29: 992-996.

27. Takahashi JM, Consani RL, Henriques GE, Nóbilo MA, Mesquita MF (2011) Effect of accelerated aging on permanent deformation and tensile bond strength of autopolymerizing soft denture liners. J Prosthodont. 20: 200-204.

28. Senna PM, Silva WJ, Faot F, Del Bel Cury AA (2011) Microwave disinfection cumulative effect of different power levels on physical properties of denture base resins. J Prosthodont 20: 606-612.

29. Minami H, Suzuki S, Ohashi H, Kurashige H, Tanaka T (2004) Effect of surface treatment on the bonding of an autopolymerizing soft denture liner to a denture base resin. Int J Prosthodont 17: 297-301.

30. Burdock GA (1998) Review of the biological properties and toxicity of bee propolis (propolis). Food Chem Toxicol 36: 347-363.

31. Bankova V, Christov R, Kujumgiev A, Marcucci MC, Popov S (1995) Chemical composition and antibacterial activity of Brazilian propolis. Z Naturforsch C 50 : 167-172.

32. Zhang Z, Guoying LV, Pan H, Wu Y, Fan L (2009) Effects of Different Drying Methods and Extraction Condition on Antioxidant Properties of Shiitake (Lentinus edodes). Food Sci Technol Res 15: 547-552.

33. Veiga VF Jr, Zunino L, Calixto JB, Patitucci ML, Pinto AC (2001) Phytochemica and antioedematogenic studies of commercial copaiba oils available in Brazil. Phytother Res 15: 476-480.

34. Maeda T, Hong G, Sadamori S, Hamada T, Akagawa Y (2012) Durability of peel bond of resilient denture liners to acrylic denture base resin. J Prosthodon Res 56: 136-141.

35. Gonçalves LM, Del Bel Cury AA, Sartoratto A, Garcia Rehder VL, Silva WJ (2012) Effects of undecylenic acid released from denture liner on Candida biofilms. J Dent Res 91: 985-989.

36. Uludamar A, Özyeșil AG, Ozkan YK (2011) Clinical and microbiological efficacy of three different treatment methods in the management of denture stomatitis. Gerodontology 28: 104-110.

37. Pinto JR, Mesquita MF, Henriques GE, de Arruda Nóbilo MAA (2002) Effect of thermocycling on bond strength and elasticity of 4 long-term soft denture liners. J Prosthet Dent 88: 516-521. 
Citation: Perchyonok VT, Souza J, Zhang S, Moodley D, Grobler S (2015) Bio-Active Nano-Diamond Designer Materials and Dentures: From Design to Application. Dentistry 5: 344. doi:10.4172/2161-1122.1000344

38. Bulad K, Taylor RL, Verran J, McCord JF (2004) Colonization and penetration of denture soft lining materials by Candida albicans. Dent Mater 20: 167-175.

39. Rodger G, Taylor RL, Pearson GJ, Verran J (2010) In vitro colonization of an experimental silicone by Candida albicans. J Biomed Mater Res B Appl Biomater 92: 226-235.

40. Garcia RM, Léon BT, Oliveira VB, Del Bel Cury AA (2003) Effect of a denture cleanser on weight, surface roughness, and tensile bond strength of two resilient denture liners. J Prosthet Dent 89: 489-494.
41. Fletcher M, Loeb GI (1979) Influence of substratum characteristics on the attachment of a marine pseudomonad to solid surfaces. Appl Environ Microbio 37: $67-72$.

42. Liu J, Hurt RH (2010) lon release kinetics and particle persistence in aqueous nano-silver colloids. Environ Sci Technol 44: 2169-2175. 